\title{
Manuscript
}

\section{Regioselective sulfation of Artemisia sphaerocephala polysaccharide: Solution conformation and antioxidant activities in vitro}

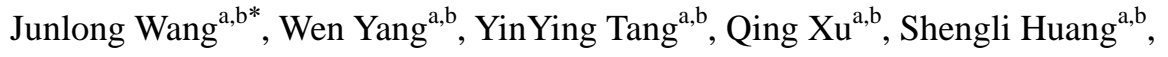 \\ Jian Yao ${ }^{\mathrm{a}, \mathrm{b}}$, Ji Zhang $^{\mathrm{a}, \mathrm{b}, \mathrm{c}}$, Ziqiang Lei $^{\mathrm{c}}$ \\ ${ }^{\text {a }}$ College of Life Science, Northwest Normal University, Lanzhou 730070, People's Republic of China \\ ${ }^{\mathrm{b}}$ Bioactive Products Engineering Research Center For Gansu Distinctive Plants, Northwest Normal University, \\ Lanzhou 730070, People's Republic of China \\ ${ }^{c}$ Key Laboratory of Eco-Environment-Related Polymer Materials Ministry of Education, College of Chemistry \\ and Chemical Engineering, Northwest Normal University, Lanzhou 730070, People's Republic of China
}

* Corresponding author: Junlong Wang Address: College of Life Science, Northwest Normal University, Anning eastroad 967 Lanzhou China

Fax:+86-0931-7971414 e-mail: nuno-vai@163.com 


\begin{abstract}
:
Regioselective modification is an effective approach to synthesize polysaccharides with different structure features and improved properties. In this study, regioselective sulfation of Artemisia sphaerocephala polysaccharide $\left(\mathrm{S}_{\mathrm{RS}} \mathrm{ASP}\right)$ was prepared by using triphenylchloromethane $(\mathrm{TrCl})$ as protecting precursor. The decrease in fractal dimension $\left(d_{\mathrm{f}}\right)$ values (1.56-2.04) of $\mathrm{S}_{\mathrm{RS}} \mathrm{ASP}$ was observed in size-exclusion chromatography combined with multi angle laser light scattering (SEC-MALLS) analysis. Compared to sample substituted at C-6, $\mathrm{S}_{\mathrm{RS}} \mathrm{ASP}$ showed a more expanded conformation of random coil, which was attributed to the breakup of hydrogen bonds and elastic contributions. Circular dichroism (CD), methylene blue (MB) and congo red (CR) spectrophotometric method and atomic force microscopy (AFM) results confirmed the conformational transition and stiffness of the chains after sulfation. $\mathrm{S}_{\mathrm{RS}} \mathrm{ASP}$ exhibited enhanced antioxidant activities in the DPPH, superoxide and hydroxyl radical scavenging assay. Sulfation at C-2 or C-3 was favorable for the chelation which might prevent the generation of hydroxyl radicals. It concluded that the degree of substitution and substitution position were the factors influencing biological activities of sulfated polysaccharides.
\end{abstract}

Keywords: Artemisia sphaerocephala; sulfated polysaccharide; regioselective synthesis; solution conformation; antioxidant activity 


\section{Introduction}

It is generally admitted that the biological activities of polysaccharides are dependent on the structure features, such as the compositions, average molecular weight, degree of substitution (DS), substitution positions and chain conformation (Zhang et al., 2011a; Wu, Li, Cui, Eskin \& Goff, 2012). The biological activities of polysaccharides may be enhanced by means of chemical or physical modifications due to their wide spectrum of activities and potential in food industry, pharmaceuticals and biomaterials (Fox, Li, Xu \& Edgar, 2011). There has been growing interests in sulfated polysaccharides due to their better biological activities, such as anticoagulant, antiviral, antitumor and immunomodulation (Nishimura et al., 1998; Yi et al., 2012). Several researchers have shown the interest in regioselective synthesis of polysaccharides derivatives with different substitution positions, i.e. cellulose (Fox, Li, Xu \& Edgar, 2011), curdlan (Zhang \& Edgar, 2014), chitosan (Skorik et al., 2003) and gellan exopolysaccharide (Redouan et al., 2011). Nishimura et al also report the C-6 sulfated chitosan and C-2/C-3 sulfated derivatives exhibit distinct activities of anticoagulant and anti-AIDS, respectively (Nishimura et al., 1998). It is note-worthy that ionic groups in different substitution positions may have a variety of functions and biological activities.

Due to the structure diversities, the relationship between biological activity and solution conformation is complicated. Interestingly, water soluble polysaccharides with similar chemical structure exhibit different chain conformations in solutions, such as helix (triple, double and single), rigid rod, flexible chain, aggregate and 
sphere-like conformation (Zhang et al., 2011a). Some researchers have concentrated on the relations between solution conformation and biological activity of natural or synthetic polysaccharides. Lentinan exists as triple helical structure in nature leading to greater antitumor activity than single helix (Tao, Zhang \& Peter, 2006). A water-soluble polysaccharide isolated from Lentinus edodes with triple helix chain presents significant antitumor bioactivities on Sarcoma180 solid tumor cell (Zhang et al., 2010). A conformational transition of branched $(1 \rightarrow 4)-\alpha$-D-glucan from Rhizoma Panacis Japonici is observed in its sulfated (S-RPS3) and phosphated (P-RPS3) derivatives. S-RPS3 and P-RPS3 significantly inhibit H-22 tumor cells growth with the transition of sphere-like conformation to random coil-like conformation (Chen et al., 2014). These results indicate that the expanded chain conformation is benefit to bioactivities of sulfated polysaccharides.

Artemisia sphaerocephala Krasch is widely distributed in Gansu province and Inner Mongolia Autonomous Region, China. In our earlier studies, A. sphaerocephala polysaccharide (ASP) is extracted and purified. ASP is an acidic polysaccharide with the uronic acid content of $16.3 \%$. Monosaccharide composition analysis showed that ASP consists of arabinose, xylose, mannose, glucose and galactose (molar ratio of 1:4.2:45.9:9.7:11.4). The weight average molecular weight $\left(M_{\mathrm{W}}\right)$ and polydispersity (PD) of ASP was measured to be $7.348 \times 10^{4}$ Da and 3.184, respectively (Wang, et al., 2015). Sulfated Artemisia sphaerocephala polysaccharide (SASP) was prepared using chlorosulfuric acid/pyridine method. SASP exhibited enhanced scavenging activities of radicals and reducing power, which was due to the high DS and more rigid 
conformation (Wang et al., 2014). Furthermore, regioselective synthesis of sulfated ASP $\left(\mathrm{S}_{\mathrm{RS}} \mathrm{ASP}\right)$ using triphenylchloromethane $(\mathrm{TrCl})$ as protecting reagent was achieved. The DS of $\mathrm{S}_{\mathrm{RS}} \mathrm{ASP}$ varied from 0.44 to 0.63 with the substitution positions at C-2 and C-3. The chemical structure was characterized by FT-IR, XPS, ${ }^{13} \mathrm{C}$ NMR, GC-MS (monosaccharide composition) and size-exclusion chromatograph combined with multi-angle laser photometer (SEC-MALLS) analysis (Wang et al., 2015).

The objective of this study is to investigate solution properties of $\mathrm{S}_{\mathrm{RS}} \mathrm{ASP}$. SEC-MALLS, circular dichroism (CD), methylene blue (MB) and congo red (CR) spectrophotometric method were employed to study the conformation parameters and transition features. Atomic force microscopy (AFM) was used to observe the shape and size of the polysaccharide molecules. Antioxidant experiments of $\mathrm{S}_{\mathrm{RS}} \mathrm{ASP}$ with different substitution positions were employed to study the relationship between solution conformation and biological activity. The antioxidant activities were evaluated in vitro including scavenging activities against 1,1-diphenyl-2-picrylhydrazyl (DPPH), superoxide and hydroxyl radicals, chelating ability and reducing power.

\section{Materials and methods}

\subsection{Materials}

All chemicals such as ascorbic acid (Vc), butyl hydroxy anisole (BHA) and ethylene diamine tetraacetic acid (EDTA) were purchased from Jingchun Industry Co. Ltd. (Shanghai, China). The chemicals were of analytical reagent without further 
purification. The extraction and purification of ASP was reported in our previous studies (Wang et al., 2010).

\subsection{Regioselective sulfation of ASP}

The regioselective sulfation of ASP was reported in our previous study (Wang et al., 2015). In brief, ASP (500 mg) was dissolved in $30 \mathrm{~mL}$ anhydrous formamide and $5 \mathrm{~mL}$ pyridine. The polysaccharide solution was stirred for $30 \mathrm{~min}$. Then, different amounts of $\operatorname{TrCl}(0.2 \sim 2.5 \mathrm{~g})$ was added and stirred at $80^{\circ} \mathrm{C}$ for $12 \mathrm{~h}$. Then, ethanol $(100$ $\mathrm{mL})$ was added to precipitate the products $\left(\mathrm{ASP}_{\mathrm{Tr} 1-5}\right)$.

Sulfated $\mathrm{ASP}_{\mathrm{Tr}}\left(\mathrm{SASP}_{\mathrm{Tr}}\right)$ was prepared according to our previous studies (Wang et al., 2014). Chlorosulfuric acid (CSA) was added dropwise in anhydrous pyridine filled in a three-necked flask, under agitating and cooling in ice water bath. $\mathrm{ASP}_{\mathrm{Tr}}$ (500 mg) with different triphenyl content was added to $20 \mathrm{~mL}$ anhydrous formamide at room temperature with stirred for $30 \mathrm{~min}$. Then sulfating reagent was added. After $3 \mathrm{~h}$, the mixture was neutralized ( $\mathrm{pH}$ value was adjusted to $7-8$ with $2 \mathrm{~mol} / \mathrm{L} \mathrm{NaOH}$ ), precipitated, dialyzed (molecular weight cutoff 8-12 kDa) and lyophilized to give sulfated $\mathrm{ASP}_{\mathrm{Tr}}\left(\mathrm{SASP}_{\mathrm{Tr} 1} \sim \mathrm{SASP}_{\mathrm{Tr} 5}\right)$.

$\mathrm{SASP}_{\mathrm{Tr}}(500 \mathrm{mg})$ was added to dichloroacetic acid $(15 \mathrm{~mL})$ portionwise for dissolution to remove the Tr group. The solution was stirred at room temperature for 1 h. Then, ice water $(100 \mathrm{~mL})$ was poured slowly. The products were collected by filtration, washed with ethanol and lyophilized. Five deprotected $\mathrm{SASP}_{\mathrm{Tr}}$ $\left(\mathrm{S}_{\mathrm{RS}} \mathrm{ASP}_{1} \sim \mathrm{S}_{\mathrm{RS}} \mathrm{ASP}_{5}\right)$ were kept in drybox before use. 
Element Analysis (Euro Vector EA3000, Leeman) was employed to determine the sulfur contents. The degree of substitution $\left(\mathrm{DS}_{\mathrm{S}}\right)$ was calculated according to the equation:

$$
D S=\frac{1.62 \times S \%}{32-1.02 \times S \%} \text { (Wang et al., 2011b) }
$$

\subsection{SEC-MALLS measurement}

The weight average molecular weight $\left(M_{\mathrm{W}}\right)$ and mean square radius of gyration $\left(\left\langle S^{2}\right\rangle_{z}\right)$ of the samples were determined by employing size-exclusion chromatograph combined with multi-angle laser photometer (SEC-MALLS, $\lambda=690 \mathrm{~nm}$; DAWN EOS, Wyatt Technology Co., USA). SEC-MALLS measurements were performed on multi-angle laser light scattering equipped with an Ultrahydrogel ${ }^{\mathrm{TM}}$ column $(7.8 \times 300$ mm, Waters, USA). An optilab refractometer (Dawn, Wyatt Technology Co., USA) was also connected with this system. Samples were dissolved in ultrapure water with the concentration of $0.01 \mathrm{mg} / \mathrm{mL}$ and filtered through a cellulose filter. The mobile phase was ultrapure water at a flow rate of $0.5 \mathrm{~mL} / \mathrm{min}$ (injection volume of $50 \mu \mathrm{L}$ ). The refractive index increment $(d \mathrm{n} / d \mathrm{c})$ value was determined to be $0.145 \mathrm{~mL} / \mathrm{g}$. The $M_{\mathrm{W}}$ and $\left\langle S^{2}\right\rangle_{\mathrm{z}}$ were calculated by the Zimm method. The Astra software (Wyatt Tech. Corp.) was used for data analysis.

\subsection{Methylene blue and congo red binding studies}

Methylene blue (MB) spectrophotometric method was carried out according to the report of Antonov with some modifications (Antonov \& Sato, 2009). MB was 
dissolved in distilled water by stirring at room temperature for $1 \mathrm{~h}$. The MB concentration was adjusted to $0.0005 \mathrm{wt} \%$ with the absorbance of 0.7-0.8 at $664 \mathrm{~nm}$ $\left(20^{\circ} \mathrm{C}\right)$. Polysaccharide/MB complexes were prepared by dropwise addition of the solution of polysaccharide to a solution of $\mathrm{MB}$, to give a final polysaccharide concentration of $0.005-0.5 \mathrm{mg} / \mathrm{mL}$. Ultraviolet-visible absorption spectra were recorded in the range from 450 to $750 \mathrm{~nm}$ (UV1000, Labtech).

Congo red (CR) spectrophotometric method was performed according to the report of Rout et al (Rout, Mondal, Chakraborty \& Islam, 2008). CR was dissolved in distilled water $(91 \mu \mathrm{mol} / \mathrm{L})$ by stirring at room temperature for $1 \mathrm{~h}$. Then, $2 \mathrm{~mL}$ polysaccharide solution $(0.2 \sim 2 \mathrm{mg} / \mathrm{mL})$ was mixed with $1 \mathrm{~mL} \mathrm{NaOH}$ and $2 \mathrm{~mL} \mathrm{CR}$ solution, to give a final $\mathrm{NaOH}$ concentration of $0.2-2 \mathrm{~mol} / \mathrm{L}$. Meanwhile, mixed solution without polysaccharide was prepared as the control. After equilibrating for 10 min, the absorbance was measured in the range from 400 to $600 \mathrm{~nm}$ at room temperature (UV1000, Labtech).

\subsection{Circular dichroism}

Circular dichroism (CD) measurements were carried out in the range from 200 to $300 \mathrm{~nm}(20 \mathrm{~nm} / \mathrm{min})$ with a Jasco J-810 spectropolarimeter (Jasco Corporation, Tokyo, Japan, $25^{\circ} \mathrm{C}$ ). A flat faced quartz sample cell of $10 \mathrm{~mm}$ optical path length was used. All observations were repeated at least 3 times with a $2 \mathrm{~nm}$ bandwidth and a time constant of $2 \mathrm{~s}$. 


\subsection{Atomic force microscopic}

Atomic force microscopic (AFM) image for sulfated polysaccharide was taken in tapping mode with a Nanoscope IIId controller (Veeco Instruments, USA). Sample was dissolved in ultrapure water and diluted to the concentration of $1 \mu \mathrm{g} / \mathrm{mL}$. Two microlitres of the solution were pipetted onto a freshly cleaved mica and air dried.

\subsection{Determination of antioxidant activities in vitro}

The DPPH and superoxide free radical scavenging activities of the sulfated samples were investigated according to our previous studies (Wang et al., 2014). The hydroxyl radical scavenging activity was determined according to the report of Melo (Melo et al., 2013). The ferrous ion chelating ability of the samples was measured according to the report of $\mathrm{Li}$ ( $\mathrm{Li}$ et al., 2013). The reducing power was measured according to the report of Qi et al (Qi et al., 2006).

All results were expressed as means \pm S.D. $(n=3)$. $E C_{50}$ value was defined as the concentration that scavenged a $50 \%$ radical. Data and $\mathrm{EC}_{50}$ values were analyzed by SPSS software 18.0 .

\section{Results and discussion}

\subsection{Solution conformation analysis}

Multi-angle light scattering technique is the most common method for conformation analysis (Yi et al., 2012). Solution conformation can be calculated according to equation (2), where $\left\langle S^{2}\right\rangle_{z}^{1 / 2}$ is mean square radius of gyration; $M$ is 
weight average molecular weight; $f$ is equation coefficient (Tao, Zhang \& Peter, 2006). The $d_{\mathrm{f}}$ value is defined as the inverse of the exponent $v$ ( 1 for rigid rod chain, 0.5 for Gaussian coil and 0.3 for three-dimensional globular shape):

$\left\langle S^{2}\right\rangle_{z}^{1 / 2}=\mathrm{f} M^{v}$

$d_{\mathrm{f}}=1 / \mathrm{v}$

In this study, we investigated the effects of molecular weight, DS and substitution positions on the solution conformation of sulfated polysaccharides using regioselective synthesis. The values of DS, $M_{\mathrm{W}}, d_{\mathrm{f}}$ and straight line fitting of the experimental data points were summarized in Table 1. Fig. 1 showed the log-log plot of $M_{\mathrm{W}}$ versus $\left\langle S^{2}\right\rangle_{z}^{1 / 2}$ of the samples. The $d_{\mathrm{f}}$ value of 2.86 showed that ASP existed as a conformation between the hard sphere $\left(d_{\mathrm{f}}=3.0\right)$ and the fully swollen branched macromolecule $\left(d_{\mathrm{f}}=2.0\right)$ in aqueous solution. Compared to ASP, a decrease in $M_{\mathrm{w}}$ was observed in all sulfated samples. The result indicated that an extensive degradation of $\mathrm{S}_{\mathrm{RS}} \mathrm{ASP}$ occurred during the reaction (Table 1). Moreover, a decrease in $d_{\mathrm{f}}$ value in all sulfated samples was observed. The $d_{\mathrm{f}}$ values of $\mathrm{S}_{\mathrm{RS}} \mathrm{ASP}_{1}-\mathrm{S}_{\mathrm{RS}} \mathrm{ASP}_{4}$ were varied from 1.56 to 1.85 . Normally, the polymer adopts a random coil conformation when $d_{\mathrm{f}}$ value between 1.5 to 2.0. It indicated that $\mathrm{S}_{\mathrm{RS}} \mathrm{ASP}_{1-4}$ exhibited as a more rigid conformation of random coil in aqueous solution. $\mathrm{S}_{\mathrm{RS}} \mathrm{ASP}_{5}$ showed relatively high $d_{\mathrm{f}}$ value of 2.04 , which lie in the range of hard sphere and the branched polymers (not swollen). The $d_{\mathrm{f}}$ value between 2-2.5 could be due to the steric hindrances of macromolecules or thermodynamic reasons (Bauer, \& Burchard, 1993). 
Table 1 Molecular weight and $d_{\mathrm{f}}$ values of sulfated derivatives

\begin{tabular}{|c|c|c|c|c|c|}
\hline Samples & DS & $\begin{array}{l}M_{\mathrm{W}} \times 10^{4} \\
\mathrm{PD}^{\mathrm{a}}\end{array}$ & Relation equation & $d_{\mathrm{f}}$ & Conformation \\
\hline ASP & $-\mathrm{b}$ & $\begin{array}{l}7.348 \\
3.18\end{array}$ & $\left\langle S^{2}\right\rangle_{z}^{1 / 2}=0.203 M_{w}^{0.35 \pm 0.027}$ & 2.86 & $\begin{array}{l}\text { between hard sphere and random } \\
\text { coil (fully swollen) }\end{array}$ \\
\hline SASP & 0.93 & $\begin{array}{l}3.203 \\
2.02\end{array}$ & $\left\langle S^{2}\right\rangle_{z}^{1 / 2}=0.141 M_{w}^{0.42 \pm 0.044}$ & 2.38 & $\begin{array}{l}\text { between hard sphere and random } \\
\text { coil (not swollen) }^{\mathrm{c}}\end{array}$ \\
\hline $\mathrm{S}_{\mathrm{RS}} \mathrm{ASP}_{1}$ & 0.61 & $\begin{array}{l}1.867 \\
2.17\end{array}$ & $\left\langle S^{2}\right\rangle_{z}^{1 / 2}=-0.950 M_{w}^{0.62 \pm 0.088}$ & 1.61 & random coil \\
\hline $\mathrm{S}_{\mathrm{RS}} \mathrm{ASP}_{2}$ & 0.57 & $\begin{array}{l}1.806 \\
2.22\end{array}$ & $\left\langle S^{2}\right\rangle_{z}^{1 / 2}=0.201 M_{w}^{0.59 \pm 0.051}$ & 1.69 & random coil \\
\hline $\mathrm{S}_{\mathrm{RS}} \mathrm{ASP}_{3}$ & 0.63 & $\begin{array}{l}3.272 \\
3.87\end{array}$ & $\left\langle S^{2}\right\rangle_{z}^{1 / 2}=0.150 M_{w}^{0.54 \pm 0.072}$ & 1.85 & random coil \\
\hline $\mathrm{S}_{\mathrm{RS}} \mathrm{ASP}_{4}$ & 0.58 & $\begin{array}{l}3.203 \\
3.55\end{array}$ & $\left\langle S^{2}\right\rangle_{z}^{1 / 2}=0.167 M_{w}^{0.64 \pm 0.067}$ & 1.56 & random coil \\
\hline $\mathrm{S}_{\mathrm{RS}} \mathrm{ASP}_{5}$ & 0.44 & $\begin{array}{l}3.255 \\
2.85\end{array}$ & $\left\langle S^{2}\right\rangle_{z}^{1 / 2}=0.361 M_{w}^{0.49 \pm 0.066}$ & 2.04 & $\begin{array}{l}\text { between hard sphere and random } \\
\text { coil (not swollen) }\end{array}$ \\
\hline $\mathrm{SASP}_{\text {cata2 }}$ & 1.24 & $\begin{array}{l}3.103 \\
1.28\end{array}$ & $\left\langle S^{2}\right\rangle_{z}^{1 / 2}=-1.99 M_{w}^{0.88 \pm 0.55}$ & 1.13 & between rigid rod and random coil ${ }^{\mathrm{d}}$ \\
\hline
\end{tabular}

${ }^{\mathrm{a}}$ Data from our previous report (Wang et al., 2015)

${ }^{\mathrm{b}}$ Not detected

${ }^{\mathrm{c}}$ Data from our previous report (Wang et al., 2010) 
${ }^{\mathrm{d}}$ Data from our previous report (Wang et al., 2014)

Some researchers have concentrated on the relations between molecular weight and solution conformation of polysaccharides. Zhang et al studied the effect of molecular weight on solution conformation of lentinan. Triple helical lentinan with high $M_{\mathrm{W}}\left(1.71 \times 10^{6} \mathrm{Da}\right)$ formed a self-entangle conformation, no ordered aggregates were observed. Conversely, short triple helical chains $\left(5 \times 10^{5} \mathrm{Da}\right)$ aligned to each other and formed "faggot-like" clusters. Molecular weight had great effect on solution conformation. Rigid conformation such as the rod-like chains with low molecular weight could form ordered aggregates as a result of the strongest interaction between each chain (Wang, Xu \& Zhang, 2008; Zhang, Li \& Zhang, 2010). The conformation change of fragmented $l$-carrageenan with shorter chain was reported by Rees et al. Low molecular weight $l$-carrageenan exhibited a disorder-order transition without the gelation that was a feature of the behavior of the natural polymer (Rees, Williamson, Frangou \& Morris, 1982). Chen et al also reported that RPS3 exhibited condensed coil conformation. The sulfated and phosphorylated RPS3 showed more extended coil conformation (Chen et al., 2014). The result indicated that the chain extensibility depended on the molecular weight, type of substituent groups and DS. This result was in accordance with our earlier report that lower $M_{\mathrm{W}}$ might lead to a rigid conformation (Wang et al., 2010; Wang et al., 2014). 


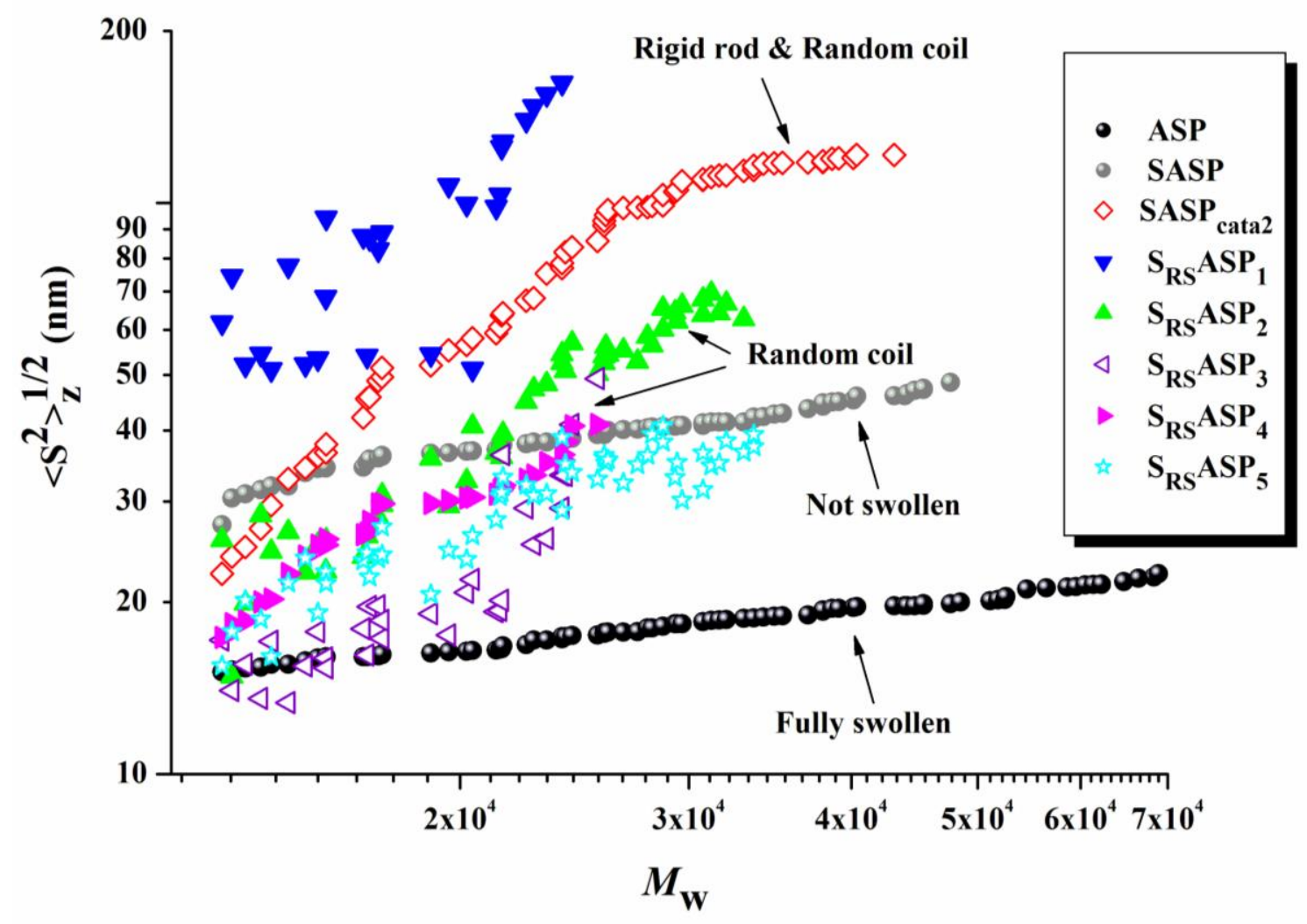

Fig. 1 Log-log plot of $M_{\mathrm{W}}$ versus $\left\langle S^{2}\right\rangle_{z}^{1 / 2}$ of ASP, SASP and $\mathrm{S}_{\mathrm{RS}} \mathrm{ASP}$ at $25^{\circ} \mathrm{C}$

For a better understanding the conformational changes, we also compared the $d_{\mathrm{f}}$ values of sulfated polysaccharides using different synthetic strategies. As already

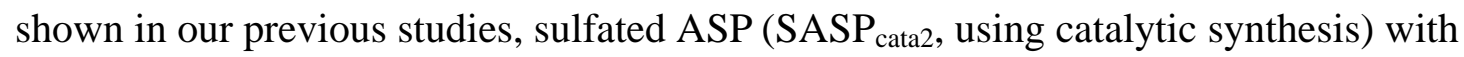
high DS of 1.24 showed a solution conformation between rigid rod and random coil (Wang et al., 2014). SASP (using conventional CSA/pyridine method) with a DS of 0.93 exhibited an internal structure between hard sphere and random coil (not swollen). Meanwhile, $\mathrm{S}_{\mathrm{RS}} \mathrm{ASP}_{5}$ with lower DS of 0.44 showed higher $d_{\mathrm{f}}$ value compared to $\mathrm{S}_{\mathrm{RS}} \mathrm{ASP}_{1}-\mathrm{S}_{\mathrm{RS}} \mathrm{ASP}_{4}$. From these results, it could be concluded that the solution conformation was strongly dependent on DS. Similar result was reported by Tao et al that a $d_{\mathrm{f}}$ value of 1.79 was obtained in sulfated polysaccharide. It might be 
due to the $-\mathrm{SO}_{3} \mathrm{H}$ groups enhance the steric hindrance between the biomacromolecule chains (Tao, Zhang \& Peter, 2006). Chen et al also reported that the sulfated and phosphorylated derivatives exhibited relatively high values of $v$ (Chen et al., 2014).

However, SASP with high DS showed a $d_{\mathrm{f}}$ value of 2.38 , which was higher than that of $\mathrm{S}_{\mathrm{RS}} \mathrm{ASP}\left(d_{\mathrm{f}}\right.$ value of $\left.1.56-2.04\right)$ with similar $M_{\mathrm{W}}$ but lower DS. It could be attributed to the fact that, in regioselective sulfation, electrostatic repulsive interactions caused by different substitution positions were not be neglected. The solution conformation was mainly governed by the dual inter-play between intramolecular hydrogen bonding and elastic contributions of polymer chains (i.e. molecular weight and electrostatic interactions of polymer chains) (Wang et al., 2014). Sulfated polysaccharides showed a significant expanded conformation upon increasing of $-\mathrm{SO}_{3} \mathrm{H}$ groups, which exhibited different intramolecular hydrogen bonding compared to nonionic polysaccharides (Fig. 2). Similar results were also reported that $-\mathrm{SO}_{3} \mathrm{H}$ groups caused the increasing of stiffness and expansion due to the electrostatic repulsion of polymer chains (Chen, Xu, Zhang \& Zeng, 2009). Compared with the samples substituted at C-6, the decrease in $d_{\mathrm{f}}$ value was attributed to the breakup of rigid hydrogen bonds from secondary hydroxyl groups in C-2 and C-3 substituted polysccharide, which evidenced a more expanded conformation in aqueous solution (Fig. 2). It was shown that the substitution position of $-\mathrm{SO}_{3} \mathrm{H}$ group was an important factor to influence the solution conformation of sulfated polysccharides. 


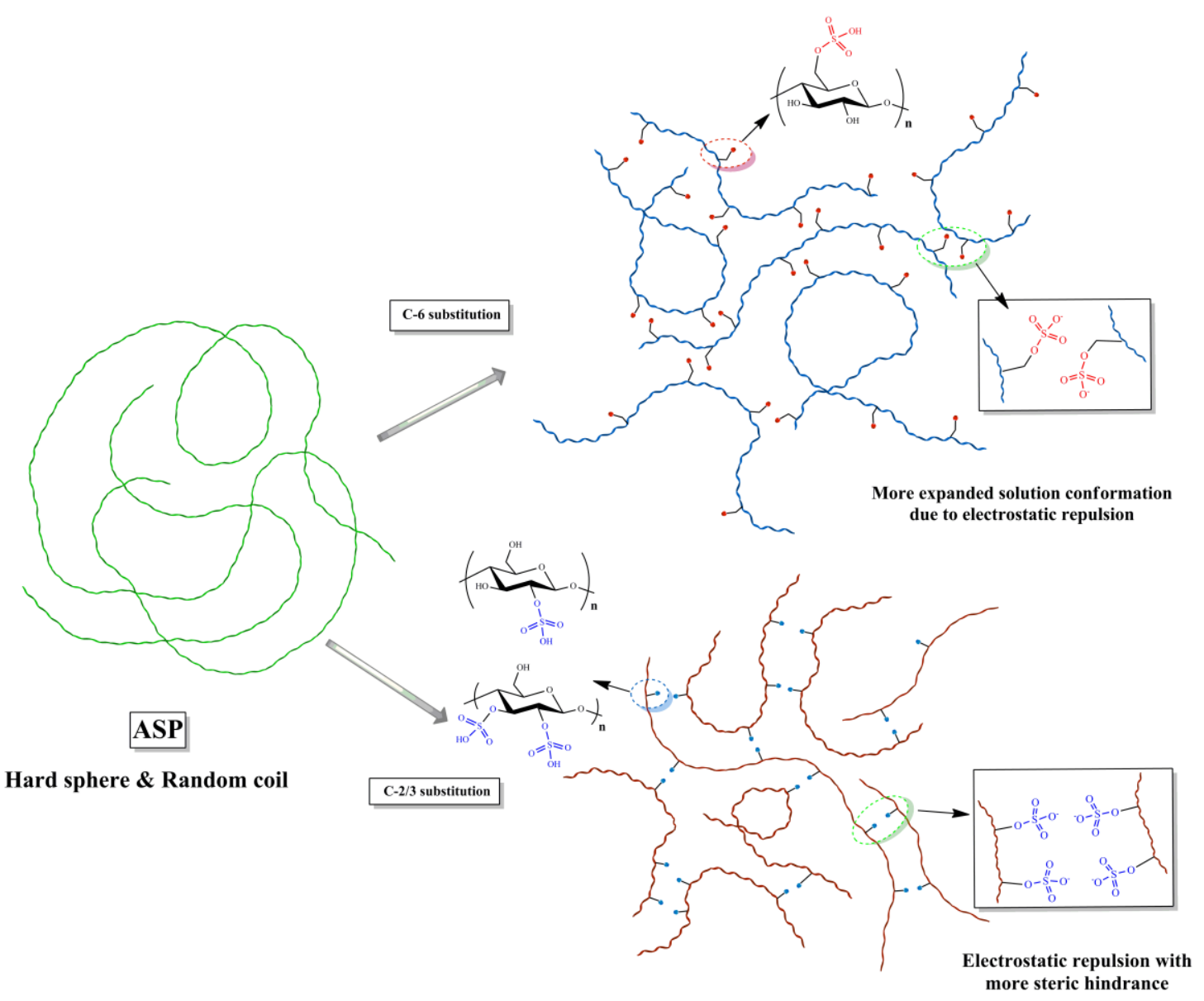

Fig. 2 Schematic representation of solution conformation transition after regioelective sulfation

\subsection{Circular dichroism $(C D)$ analysis}

$\mathrm{CD}$ is employed as a convenient method for the characterization of conformational changes of macromolecules with optical activity, which may affect the polarizability and orientation of the chromophores. The CD spectra were shown in Fig. 3 in which $\mathrm{SASP}_{\text {cata2 }}$ and $\mathrm{S}_{\mathrm{RS}} \mathrm{ASP}_{4}$ was compared with $\mathrm{ASP}$ at neutral $\mathrm{pH}$ value. The CD spectrum of ASP exhibited a negative peak maximum at $209 \mathrm{~nm}$, which might attribute to the $n-\pi^{*}$ transition of carboxylate. It was in accordance with our earlier report that ASP is an acidic polysaccharide (Wang et al., 2010). 


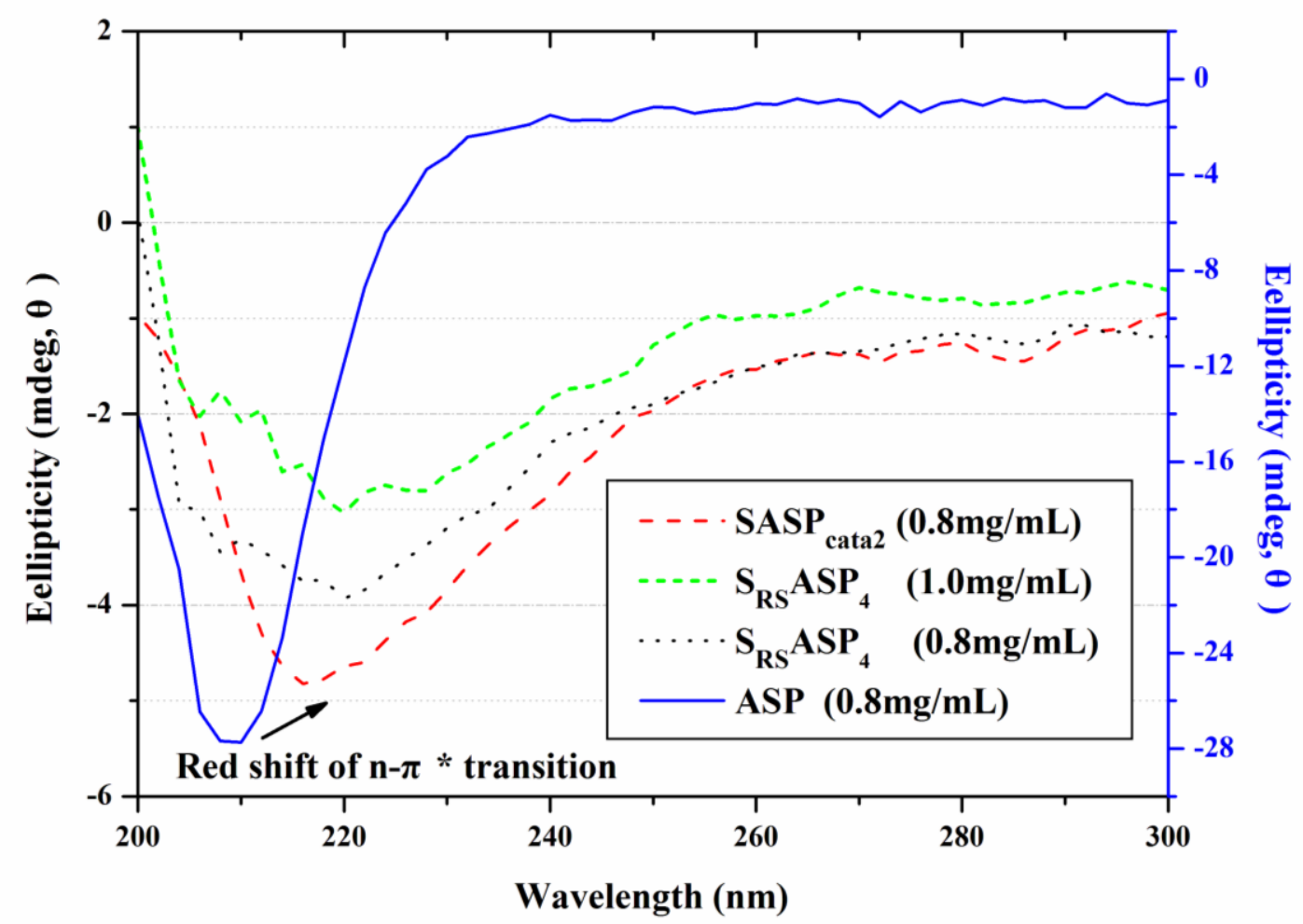

Fig. 3 Circular dichroism spectra of ASP and its sulfated derivatives at $25^{\circ} \mathrm{C}$

Like ASP, $\mathrm{S}_{\mathrm{RS}} \mathrm{ASP}_{4}$ exhibited negative ellipticity in the concentration of 0.8 and $1.0 \mathrm{mg} / \mathrm{mL}$ (Fig. 3). However, in comparison with ASP, the maximum was decreased and red-shifted to $219 \mathrm{~nm}$. Our previous report also showed that a decrease of the ellipticity and red shift of $n-\pi^{*}$ transition at $216 \mathrm{~nm}$ was observed in $\mathrm{SASP}_{\text {cata2 }}$ (Wang et al., 2014). The signal intensity was approximately 6 times less for $\mathrm{SASP}_{\text {cata2 }}$ and $\mathrm{S}_{\mathrm{RS}} \mathrm{ASP}_{4}$ compared with ASP. The new ellipticity and shift to a lower energy excitation wavelength near $220 \mathrm{~nm}$ could be attributed to chromophore contributions of the introduced $-\mathrm{SO}_{3} \mathrm{H}$ group of sulfated polysaccharides (Forget et al., 2013). CD scans agreed well with the SEC-MALLS result that the red shift of $n-\pi^{*}$ transition and the decrease in ellipticity indicated the appearance of $\mathrm{S}=\mathrm{O}$. It therefore appeared that 
the sulfation of the polysaccharide promoted a transition of the chains leading to an expanded conformation.

\subsection{Polysaccharide-methylene blue interactions}

The studies of the binding of dyes to polymers have become a common technique to identify molecular conformation of water soluble macromolecules, such as polysaccharides, nucleic acids and proteins (Antonov \& Sato, 2009). Methylene blue (MB), a planar cationic phenotiazinium dye, to form complex in the presence of an anionic polysaccharide results in changes in the absorption spectrum of the dye (Girod et al., 2004). MB displayed a characteristic absorption band centered at 664 $\mathrm{nm}$ together with a shoulder at $619 \mathrm{~nm}$, which was attributed to the monomeric and dimeric dye, respectively (Michon, Konate, Cuvelier \& Launay, 2002). The evolution of the absorption values determined at $664 \mathrm{~nm}\left(A_{664}\right)$ and $554 \mathrm{~nm}\left(A_{554}\right)$ as a function of sample concentrations were investigated. Fig. 4A showed the absorption spectra of $\mathrm{S}_{\mathrm{RS}} \mathrm{ASP}_{4}-\mathrm{MB}$ complexes which contains various amounts of $\mathrm{S}_{\mathrm{RS}} \mathrm{ASP}_{4}$ $(0.005-0.5 \mathrm{mg} / \mathrm{mL})$ in a definite concentration of MB. As shown in Fig. 4A, remarkable hypochromic effect at $664 \mathrm{~nm}$ and hyperchromic effect at $554 \mathrm{~nm}$ were observed especially for the sample with higher polysaccharide concentrations. $A_{664}$ decreased and $A_{554}$ increased as $\mathrm{S}_{\mathrm{RS}} \mathrm{ASP}_{4}$ concentration increased up to a limit of 0.05 $\mathrm{mg} / \mathrm{mL}$, indicating that there was an equilibrium state between sulfated polysaccharide and MB (Fig. 4B). It could be assumed that all the positively charged MB molecules were saturated by sulfated groups. Girod et al also reported a similar 
result of an 'optimal' concentration in $l$-carrageenan/MB interactions (Girod et al., 2004).

It was reported that $\mathrm{MB}$ and sulfated polysaccharides could form metachromatic complexes in which MB molecules in parallel absorption near $560 \mathrm{~nm}$. Long-range forces involving $\mathrm{MB}$ and $\mathrm{H}_{2} \mathrm{O}$ could take place and maintain the planar MB molecules relatively close to each other (Michon, Konate, Cuvelier \& Launay, 2002). This equilibrium could be reversed on heating and the spectrum of the complex then approached to that of the MB alone. It indicated that the MB molecules bound to the anionic polymer in the rigid conformation (i.e. double-helix), but not in the flexible form (Rees, Williamson, Frangou \& Morris, 1982; Zhang et al., 2011a). The dissociation of a duplex ct-DNA into two single strands induced by heating was also reported by Mudasir et al in nucleic acid-MB binding test. The denaturation temperature was depended on the strength and mode of nucleic acid-MB interactions (Mudasir et al., 2010). In this case, we investigated the effect of temperature on the conformational transition. The evolutions of $A_{664}$ and $A_{554}$ as a function of temperature $\left(20-80^{\circ} \mathrm{C}\right)$ were shown in Fig. $4 \mathrm{C}$ and $4 \mathrm{D}$. The degree of hypochromicity at $554 \mathrm{~nm}$ increased with the increasing of temperature. As can be seen from Fig. 4D, the hypochromic effect of $A_{554}$ decreased from 0.231 to 0.128 by increasing temperature from $40^{\circ} \mathrm{C}$ to $80^{\circ} \mathrm{C}$. On the contrary, the hyperchromic effect of $\mathrm{MB}$ solution in the presence of $\mathrm{S}_{\mathrm{RS}} \mathrm{ASP}_{4}$ was found to increase from 0.329 to 0.896 when the temperature increased from $40^{\circ} \mathrm{C}$ to $80^{\circ} \mathrm{C}$. This was in accordance with our earlier result that the transition temperature of solution conformation was near $50^{\circ} \mathrm{C}$ in polysaccharide-MB 
complexes (Wang et al., 2014). The remarkable hypochromic effect at $554 \mathrm{~nm}$ indicated the existence of strong interaction between sulfated polysaccharide and MB molecules, most probably via electrostatic attraction. The interaction of binding resulted in ordered stacking of $\mathrm{MB}$ and stabilized electronically in the helical conformation of sulfated polysaccharide. Compared to $\mathrm{SASP}_{\text {cata2 }}$ with higher DS and more rigid conformation, $\mathrm{S}_{\mathrm{RS}} \mathrm{ASP}_{4}$ showed greater hyperchromic and hypochromic effects at $664 \mathrm{~nm}$ and $554 \mathrm{~nm}$, respectively. It might be due to the lower DS and more flexible conformation of $\mathrm{S}_{\mathrm{RS}} \mathrm{ASP}_{4}$. However, $\mathrm{S}_{\mathrm{RS}} \mathrm{ASP}_{4}$ with higher $d_{\mathrm{f}}$ value of 1.56 showed less hypochromic effect at $664 \mathrm{~nm}$ compared to SASP with higher DS but lower $d_{\mathrm{f}}$ value of 2.38 (Wang et al., 2014). Rees et al reported that the driving forces toward binding on the polymer from a dye-stacking tendency which might involve the electrostatic interactions due to the rigidity of the solution conformation (Rees, Williamson, Frangou \& Morris, 1982). It could be concluded that DS and $d_{\mathrm{f}}$ values are key factors to influence the absorption spectra of dye-polysaccharide complexes. 

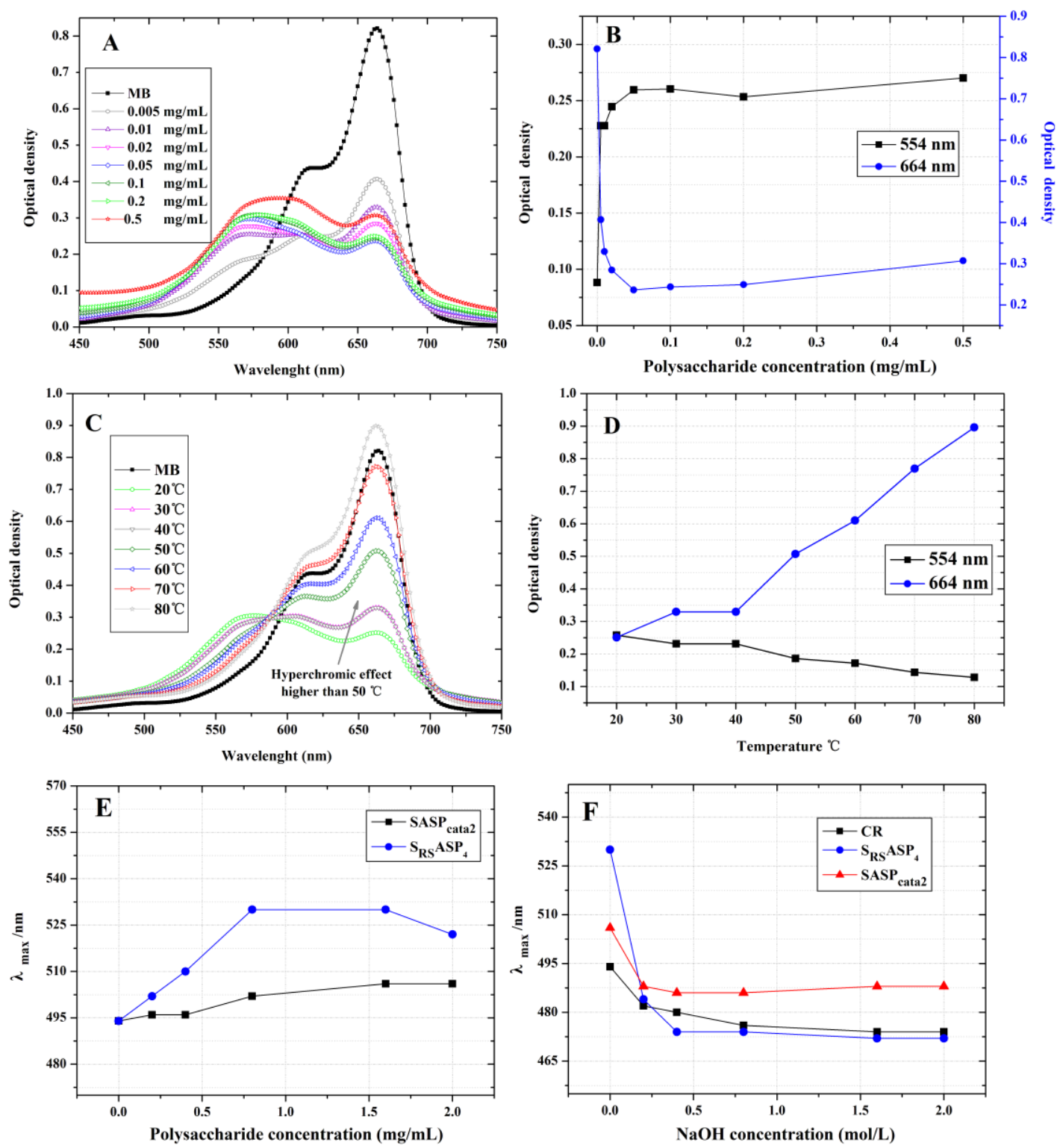

Fig. 4 Dye-polysaccharide binding tests (A) Absorption spectra of MB measured from $450 \mathrm{~nm}$ to $750 \mathrm{~nm}$ at different concentrations of $\mathrm{S}_{\mathrm{RS}} \mathrm{ASP}_{4}$ at $20^{\circ} \mathrm{C}$ (B) Evolution of absorption values at $664 \mathrm{~nm}$ and $554 \mathrm{~nm}$ for $\mathrm{S}_{\mathrm{RS}} \mathrm{ASP}_{4}$ as a function of polysaccharide concentrations. (C) Absorption spectra of $\mathrm{MB}$ at different temperatures with $\mathrm{S}_{\mathrm{RS}} \mathrm{ASP}_{4}$ concentration of 0.05 $\mathrm{mg} / \mathrm{mL}$. (D) Evolution of absorption values at $664 \mathrm{~nm}$ and $554 \mathrm{~nm}$ for $\mathrm{S}_{\mathrm{RS}} \mathrm{ASP}_{4}$ as a function of temperatures. (E) Evolution of absorption values of $\mathrm{S}_{\mathrm{RS}} \mathrm{ASP}_{4}-\mathrm{CR}$ as a function of polysaccharide concentrations at $20^{\circ} \mathrm{C}(\mathrm{F})$ Evolution of absorption values of $\mathrm{S}_{\mathrm{RS}} \mathrm{ASP}_{4}$ - $\mathrm{CR}$ as a function of $\mathrm{NaOH}$ concentrations at $20^{\circ} \mathrm{C}$ 


\subsection{Polysaccharide-congo red interactions}

The conformational transition of the sulfated polysaccharides was determined by employing CR-polysaccharide complexes spectrophotometric method at various alkali concentrations. As shown in Fig. 4E, compared to the curve of $\mathrm{SASP}_{\text {cata2 }}$ obtained in our earlier report, the maximum in the visible absorption $\left(\lambda_{\max }\right)$ of $\mathrm{S}_{\mathrm{RS}} \mathrm{ASP}_{4}-\mathrm{CR}$ complexes red-shifted to longer wavelengths at the polysaccharide concentrations range of $0-2.0 \mathrm{mg} / \mathrm{mL}$. It was indicated that $\mathrm{S}_{\mathrm{RS}} \mathrm{ASP}_{4}$ adopted a highly ordered conformation in CR-polysaccharide complex. Then, the complex formation of $\mathrm{S}_{\mathrm{RS}} \mathrm{ASP}_{4}-\mathrm{CR}$ was determined from the red-shift in alkaline conditions at the polysaccharide concentration of $1 \mathrm{mg} / \mathrm{mL}$. The $\lambda_{\max }$ of $\mathrm{S}_{\mathrm{RS}} \mathrm{ASP}_{4}-\mathrm{CR}$ decreased substantially at the $\mathrm{NaOH}$ concentrations range of $0-2.0 \mathrm{M}$, which indicated that the highly ordered conformation of $\mathrm{S}_{\mathrm{RS}} \mathrm{ASP}_{4}$ might convert into a flexible conformation (Fig. 4F).

Generally, at the $\mathrm{NaOH}$ concentration below $0.1 \mathrm{M}$, the $\lambda_{\max }$ red-shifts to longer wavelength (beyond $505 \mathrm{~nm}$ ) which is attribute to a triple-helical structure of polysaccharide (Zhao et al., 2014). The $\lambda_{\max }$ of CR were largely red-shifted (from 500 to $514 \mathrm{~nm}$ ) by the presence of Pleurotus florida polysaccharide (PFPSIN) in $0.1 \mathrm{M}$ $\mathrm{NaOH}$ solution. It suggested that PFPSIN had triple helical structure (Rout, Mondal, Chakraborty \& Islam, 2008). Zhang et al also showed that Lentinus edodes polysaccharide existed as a triple-helix in $0.1 \mathrm{M} \mathrm{NaOH}$ (Zhang et al., 2010). Our result showed the order-disorder transition of the CR-polysaccharide complexes due to the 
breakage of intermolecular hydrogen bonds in alkaline solution. Thus, it could be concluded that $\mathrm{S}_{\mathrm{RS}} \mathrm{ASP}_{4}$ showed a rigid conformation as evidenced in SEC-MALLS. However, no triple-helical conformation was detected. Similar result was reported that longan pulp polysaccharide showed a transition from rigid conformation to flexible conformation due to the depolymerization of polysaccharide-dye complex (Yi et al., 2012).

\subsection{AFM}

AFM has been widely employed to investigate the molecular and supramolecular structures of macromolecules, especially for the samples with soft biological surface (Yi et al., 2012). ASP exhibited as a linear molecule or network structure at the concentrations of $1 \mu \mathrm{g} / \mathrm{mL}$ in AFM image (Zhang et al., 2007). Fig. 5 showed the AFM images of $\mathrm{S}_{\mathrm{RS}} \mathrm{ASP}_{4}$. In order to avoid the influence of tip broadening effects, molecular height in section analysis was used to characterize the size of particles. The images revealed that $\mathrm{S}_{\mathrm{RS}} \mathrm{ASP}_{4}$ was mainly spherical lumps and rod-like morphologies. The particles were inhomogeneous with the mean height of $2.406 \pm 0.79 \mathrm{~nm}$ and mean diameter of $95.7 \pm 17.9 \mathrm{~nm}$ in particle analysis. The width and height of the rod-like structures ranged from 70 to $160 \mathrm{~nm}$ and 1.2 to $1.8 \mathrm{~nm}$ in section analysis, respectively. Generally, the height of a single polysaccharide chain is about $0.1-1 \mathrm{~nm}$. It suggested that intermolecular and intramolecular aggregation might be involved in $\mathrm{S}_{\mathrm{RS}} \mathrm{ASP}_{4}$. It was ascribed to the hydroxyl and $-\mathrm{SO}_{3}{ }^{-}$groups on the chains of the $\mathrm{S}_{\mathrm{RS}} \mathrm{ASP}_{4}$ providing the strong intermolecular and intramolecular interaction. However, 
linear molecules and tangled network structures were not observed in $\mathrm{S}_{\mathrm{RS}} \mathrm{ASP}_{4}$. Based on the result, we could conclude that there was remarkable effect on the molecule conformation for the polysaccharides after sulfation.

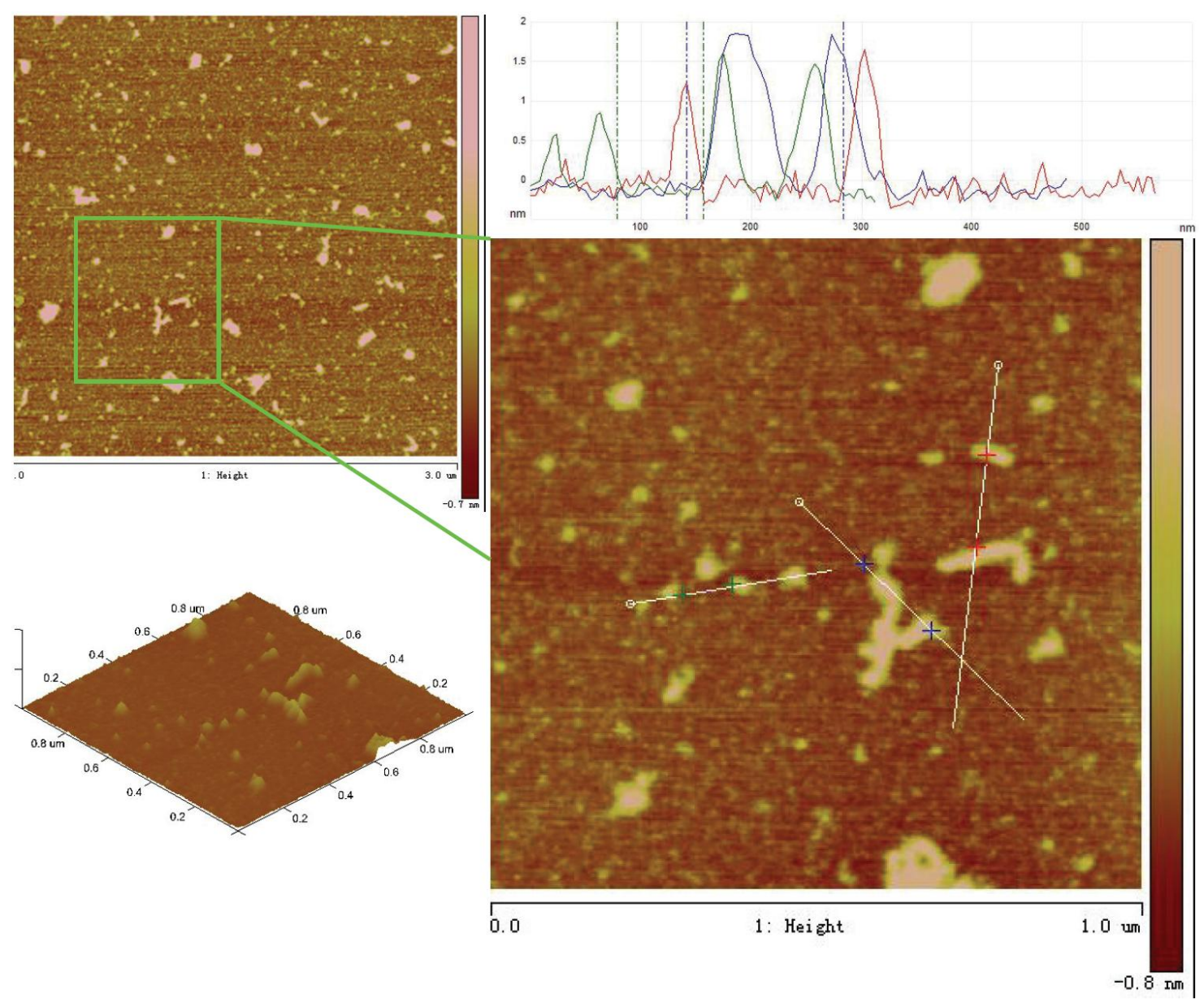

Fig. $52 \mathrm{D} / 3 \mathrm{D}$ AFM images and section analysis of $\mathrm{S}_{\mathrm{RS}} \mathrm{ASP}_{4}$ at the concentration of $1 \mu \mathrm{g} / \mathrm{mL}$

\subsection{Evaluation of antioxidant activities in vitro}

It was reported that the functional groups such as $-\mathrm{SO}_{3}{ }^{-},-\mathrm{OH}$ and $-\mathrm{COOH}$ were responsible for the biological activities of polysaccharides. The antioxidant activities of sulfated polysaccharides were related to many factors, such as substitution groups, average molecular weight, DS and substitution positions (Melo et al., 2013). In order 
to study the effect of regioselective synthesis on the bioactivity of sulfated polysaccharides, antioxidant experiments of sulfated ASP with different substitution positions were carried out. $\mathrm{S}_{\mathrm{RS}} \mathrm{ASP}_{4}$ and $\mathrm{SASP}_{\text {cata2 }}$ were selected to evaluate the antioxidant activities for their similar $M_{\mathrm{W}}\left(3.203\right.$ and $3.103 \times 10^{4} \mathrm{Da}$, respectively) but different DS and substitution positions. The data of $\mathrm{SASP}_{\text {cata2 }}$ was reported in our previous study (Wang et al., 2014). Methods in the different stages including reducing power (initiation), chelation of iron ion (propagation) and scavenging of DPPH, superoxide and hydroxyl radicals (termination) were employed to evaluate the antioxidant activities in vitro. $\mathrm{EC}_{50}$ value was defined as the concentration that scavenged a $50 \%$ radical.

\subsubsection{DPPH radicals scavenging activity}

The scavenging abilities of sulfated ASP on DPPH radical were shown in Fig. 6A and compared with Vc and ASP. The result indicated that all samples showed dose-dependent features in the concentration ranges of $0.02-5 \mathrm{mg} / \mathrm{mL}$. Both $\mathrm{SASP}_{\text {cata2 }}$ and $\mathrm{S}_{\mathrm{RS}} \mathrm{ASP}_{4}$ had abilities on scavenging DPPH radicals, the $\mathrm{EC}_{50}$ values were 2.007 and $3.988 \mathrm{mg} / \mathrm{mL}$, respectively. Sulfated ASP showed higher scavenging abilities than ASP $\left(\mathrm{EC}_{50}\right.$ of $\left.4.946 \mathrm{mg} / \mathrm{mL}\right)$ but lower than $\mathrm{Vc}\left(\mathrm{EC}_{50}\right.$ of $\left.0.631 \mathrm{mg} / \mathrm{mL}\right) . \mathrm{SASP}_{\text {cata2 }}$ exhibited lower $\mathrm{EC}_{50}$ value than $\mathrm{S}_{\mathrm{RS}} \mathrm{ASP}_{4}$ which indicated that high DS could enhance the scavenging abilities of DPPH radicals. Redouan et al reported that higher uronic acids content and sulfate groups could enhance the antioxidant activity of gellan exopolysaccharide (Redouan et al., 2011). Other authors also reported that 
modification of xanthouronan by regioselective oxidation could considerably enhance the anti-DPPH radical properties (Delattre et al., 2015). The addition of anionic groups at C-2 and C-3 such as carboxylate and sulfate could activate the hydrogen atom of the anomeric carbon and reduce the intramolecular/intermolecular hydrogen bond, thus promoting hydrogen-donating abilities (Melo et al., 2013). It was in accordance with our earlier result that $\mathrm{SASP}_{\text {cata2 }}$ with highest DS exhibited the best scavenging DPPH radical activity (Wang et al., 2014).

\subsubsection{Superoxide radical scavenging activity}

The superoxide radicals scavenging abilities of samples showed significance in a concentration-dependent fashion (Fig. 6B). The scavenging effect of the samples increased in the order of ASP, $\mathrm{S}_{\mathrm{RS}} \mathrm{ASP}_{4}$ and $\mathrm{SASP}_{\text {cata2 }}$ with the $\mathrm{EC}_{50}$ values of 1.013, 0.131 and $0.027 \mathrm{mg} / \mathrm{mL}$, respectively. Similar result of sulfated polysaccharides with the $\mathrm{EC}_{50}$ values of $0.9-0.02 \mathrm{mg} / \mathrm{mL}$ was reported. Carboxylic groups with strong electron-withstanding ability in the modified polysaccharides enhanced the activity of scavenging superoxide radical (Redouan et al., 2011). Qi et al also reported that the acetylated and benzoylated ulvans could terminate radical chain reactions by stabilization of free radicals in carbohydrate chains and exhibit more pronounced superoxide radical scavenging abilities (Qi et al., 2006). Zhang et al reported that sulfated Auricularia auricular polysaccharides showed stronger scavenging activity on the superoxide radical than $\mathrm{Vc}$ at the concentration of $2.0 \mathrm{mg} / \mathrm{mL}$ (Zhang et al., 2011b). These results concluded that anionic polysaccharides showed greater 
antioxidant activity which is related to the contents of the substitution groups.
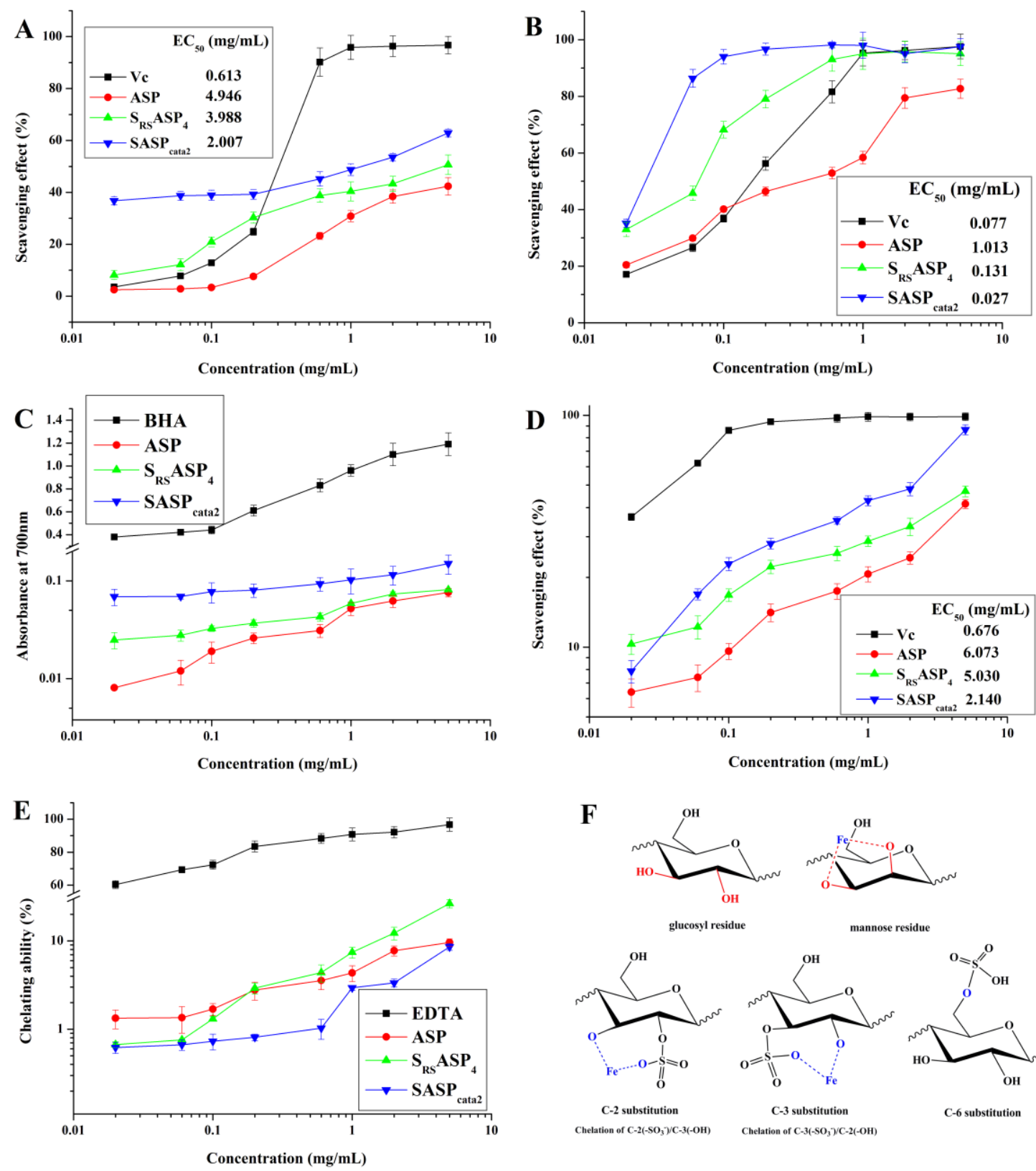
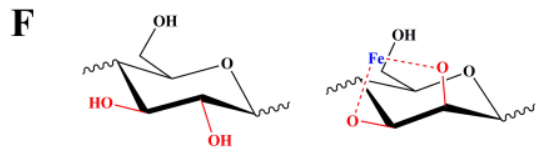

glucosyl residue
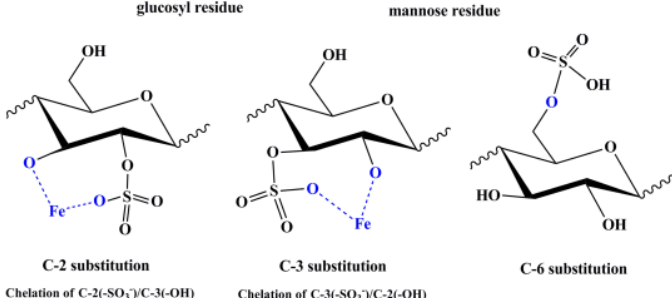

Fig. 6 Antioxidant effect of ASP and its sulfated derivatives. Samples with different substitution

positions were selected. (A) scavenging activity of DPPH radicals; (B) scavenging activity of superoxide radicals; (C) reducing power evaluation; (D) scavenging activity of hydroxyl radicals;

(E) ferrous ions chelating effect; $(F)$ Schematic representation of the formation of chelates; data are presented as mean values $(\mathrm{n}=3)$. 


\subsubsection{Reducing power}

The reducing abilities of the samples were shown in Fig. 6C. Upon comparing with BHA, the lower reducing agent potency of the samples could be observed. At all the concentrations, $\mathrm{SASP}_{\text {cata2 }}$ and $\mathrm{S}_{\mathrm{RS}} \mathrm{ASP}_{4}$ were more potent than ASP. The reducing power of ASP, $\mathrm{S}_{\mathrm{RS}} \mathrm{ASP}_{4}$ and $\mathrm{SASP}_{\text {cata2 }}$ was $0.052,0.059$ and 0.102 at the concentration of $1 \mathrm{mg} / \mathrm{mL}$, respectively. The reducing power of the polysaccharides with different structure features had been shown to exert antioxidant action by interrupting the free radical chain by donating a hydrogen atom (Li et al., 2013). Melo and colleagues proved that sulfated polysaccharides from Dictyopteris justii presented great reducing power. Polyanion, a good electron donor, with higher density of negative charges showed better reducing power (Melo et al., 2013).

\subsubsection{Hydroxyl radical scavenging activity and chelating effect on ferrous ions}

The hydroxyl radical is very active in reactive oxygen species (ROS), making it very harmful to bio-molecules in organism such as proteins, DNA and lipids. Hydroxyl radical can be generated by the reaction between transition metals and the superoxide ion in the Fenton reaction. Two types of antioxidant mechanism were reported: scavenging of hydroxyl radical and suppression against hydroxyl radical generation (Li et al., 2013; Melo et al., 2013; Zhang et al., 2011b). Fig. 6D described the scavenging activity on hydroxyl radical of the samples. Compared to ASP $\left(\mathrm{EC}_{50}\right.$ of $6.073 \mathrm{mg} / \mathrm{mL}), \mathrm{S}_{\mathrm{RS}} \mathrm{ASP}_{4}$ and $\mathrm{SASP}_{\text {cata2 }}$ showed improved scavenging performances 
with the $\mathrm{EC}_{50}$ values of 5.03 and $2.14 \mathrm{mg} / \mathrm{mL}$, respectively.

The second mechanism is more related to the transition of metal ions to specific metal complexes, which may prevent metal ions from interacting with $\mathrm{H}_{2} \mathrm{O}_{2}$, thus preventing the generation of hydroxyl radicals. In this case, the chelating ability of metal ions such as ferrous ions may affect the antioxidant activity. Fig. 6E showed a concentration-dependent manner of the ferrous ions chelating ability in all of the samples. At the concentration of $0.02-0.2 \mathrm{mg} / \mathrm{mL}$, the chelating abilities of sulfated samples were weaker than ASP. At the higher concentration ranges of $0.6-5 \mathrm{mg} / \mathrm{mL}$, $\mathrm{S}_{\mathrm{RS}} \mathrm{ASP}_{4}$ showed the strongest chelating ability of $4.4-26.5 \%$. Qi et al reported the great chelating ability ranged from $37 \%$ to $78 \%$ of acetylated ulvan at the concentration of $0.31-1.88 \mathrm{mg} / \mathrm{mL}$ (Qi et al., 2006). Similar result was reported that a moderate chelating ability of $23.7 \%$ and $27.6 \%$ was achieved in the sulfated polysaccharides extracted from Dictyopteris justii. Although many articles correlated the enhanced chelating ability to the presence of substituent groups, the sulfated glucans exhibited no ferric chelating activity (Melo et al., 2013). It was possible that the antioxidant ability was not a function of a one factor but a multiple action of many factors, such as DS, $M_{\mathrm{W}}$ and substitution patterns. Melo et al also noticed that both of sulfur content and the distribution of sulfate groups could influence the antioxidant activity (Melo et al., 2013).

Monosaccharides are the building blocks of polysaccharide which might have a great influence on chelating ability. In ASP, mannose, glucose and galactose are the main compositions of the polysaccharide chain (Wang et al., 2015). As we know, 
neigbouring cis-hydroxyl groups possess higher coordination activity. Mannose residue in polysaccharide chain with cis-2,3-dihydroxy is beneficial to form $\mathrm{Fe}^{2+}$-polysaccharide chelate in chelating experiment (Fig. 6F). In our previous studies, mannose was the dominant component in ASP. The ratio of mannose to glucose was 4.71 (45.9/9.74). However, glucose residue was the dominant monosaccharide in all sulfated samples. The ratio of mannose to glucose was $0.848(12.41 / 14.62)$ for $\mathrm{S}_{\mathrm{RS}} \mathrm{ASP}_{4}$ (Wang et al., 2015). This could explain the result observed in Fig. 6E that ASP showed higher chelating ability than $\mathrm{S}_{\mathrm{RS}} \mathrm{ASP}_{4}$ and $\mathrm{SASP}_{\text {cata2 }}$ at low concentration. Moreover, the effect of substitution positions on the chelating activity should not be neglected. $\mathrm{S}_{\mathrm{RS}} \mathrm{ASP}_{4}$ with the $-\mathrm{SO}_{3}{ }^{-}$groups substituted at $\mathrm{C}-2$ and $\mathrm{C}-3$ might exhibit distinct chelating ability. Sulfate group at C-2 or C-3 was favorable for the formation of chelation with hydroxyl at ortho position, such as $\mathrm{C}-2\left(-\mathrm{SO}_{3}{ }^{-}\right) / \mathrm{C}-3(-\mathrm{OH})$ and C-3(- $\left.\mathrm{SO}_{3}{ }^{-}\right) / \mathrm{C}-4(-\mathrm{OH})$ chelates. Contrarily, sulfate group at C-6 might show weaker $\mathrm{Fe}^{2+}$ binding capacity due to the feature of exocyclic substituent group (Fig. 6F). The results indicated that the coordinated active sites were mainly supplied with sulfate group at $\mathrm{C}-2 / \mathrm{C}-3$ and neigbouring cis- $\mathrm{OH}$ of main chain. It could be concluded that monosaccharide composition and substitution groups in a favorable structure-function configuration could show greater metal chelating activity in sulfated polysacchaides. Thus, further investigation is necessary to clarify this point.

\section{Conclusion}

In this study, a decrease in $d_{\mathrm{f}}$ values (1.56-2.04) of all sulfated samples was 
observed. It attributed to the breakup of rigid hydrogen bonds from secondary hydroxyl groups in C-2 and C-3 substituted polysccharides, which evidenced a more expanded conformation in aqueous solution. The red shift of $n-\pi^{*}$ transition and the decrease in ellipticity indicated a transition of the chains leading to an expanded conformation in $\mathrm{CD}$ analysis. $\mathrm{S}_{\mathrm{RS}} \mathrm{ASP}$ showed greater hyperchromic effect at $664 \mathrm{~nm}$ attributed to the low DS and more flexible conformation in MB binding experiments. It was indicated that DS and $d_{\mathrm{f}}$ values are key factors to influence the absorption spectra of dye-polysaccharide complexes.

Moreover, antioxidant evaluation revealed that $\mathrm{S}_{\mathrm{RS}} \mathrm{ASP}_{4}$ could enhance the DPPH, superoxide and hydroxyl radicals scavenging activities and chelating abilities in vitro. In summary, our results indicated that the combined action of subsitution position and DS may influence the biologcal activities of modified polysaccharides. Further studies about the antitumor activities of sulfated ASP with different subsitution positions are in progress.

\section{Acknowledgments}

Financial support of this research from National Science Foundation of China (21204073 and 51463022) and Natural Science Foundation of Gansu Province (1308RJZA200) are gratefully acknowledged. We would also like to thank Prof. Ruibin Guo (Northwest Normal University) for the use of SEC-MALLS. 


\section{References}

Antonov, Y.A., Sato, T. (2009). Macromolecular complexes of the main storage protein of Vicia faba seeds with sulfated polysaccharide. Food Hydrocolloids, 23, 996-1006.

Bauer, J., Burchard, W. (1993). Determination of scaling properties of randomly branched polycyanurates by combined SEC/LALLS/VISC. Macromolecules, 26, 3103-3107.

Chen, C., Wu, W.H., Xu, X.J., Zhang, L.N., Liu, Y., Wang, K.B. (2014). Chain conformation and anti-tumor activity of derivatives of polysaccharide from Rhizoma Panacis Japonici.

Carbohydrate Polymers, 105, 308-316

Chen, X.Y., Xu, X.J., Zhang, L.N., Zeng, F.B. (2009). Chain conformation and anti-tumor activities of phosphorylated ( $1 \rightarrow 3)-\beta$-D-glucan from Poria cocos. Carbohydrate Polymers, 78, 581-587.

Delattre, C., Pierre, G., Gardarin, C., Traikia, M., Elboutachfaiti, R., Isogai, A., Michaud, P. (2015). Antioxidant activities of a polyglucuronic acid sodium salt obtained from TEMPO-mediated oxidation of xanthan. Carbohydrate Polymers, 116, 34-41.

Forget, A., Christensen, J., Lüdeke, S., Kohler, E., Tobias, S., Matloubi, M., Thomann, R., Shastri, V.P. (2013). Polysaccharide hydrogels with tunable stiffness and provasculogenic properties via alpha-helix to beta-sheet switch in secondary structure. PNAS, 110, 12887-12892.

Fox, S.C., Li, B., Xu, D.Q., Edgar, K.J. (2011). Regioselective esterification and etherification of cellulose: A review. Biomacromolecules, 12, 1956-1972.

Girod, S., Boissere, M., Longchambon, K., Begu, S., Tourne, P.C. Devoisselle, J. M. (2004). Polyelectrolyte complex formation between iota-carrageenan and poly(L-lysine) in dilute aqueous solutions: a spectroscopic and conformational study. Carbohydrate Polymers, 55, 
$37-45$.

Li, B., Liu, S., Xing, R., Li, K.C., Li, R.F., Qin, Y.K., Wang, X.Q., Wei, Z.H., Li, P.C. (2013).

Degradation of sulfated polysaccharides from Enteromorpha prolifera and their antioxidant activities. Carbohydrate Polymers, 92, 1991-1996.

Melo, K.R., Camara, R.B., Queiroz, M.F., Vidal, A.A., Lima, C.R., Melo, S.R.F., Almeida, L.J., Rocha, H.A. (2013). Evaluation of sulfated polysaccharides from the brown seaweed Dictyopteris justii as antioxidant agents and as inhibitors of the formation of calcium oxalate crystals. Molecules, 18, 14543-14563.

Michon, C., Konate, K., Cuvelier, G., Launay, B. (2002). Gelatin carrageenan interactions in coil and ordered conformations followed by a methylene blue spectrophotometric method. Food Hydrocolloids, 23, 613-618.

Mudasir, Wahyuni, E.T., Tjahjono, D.H., Yoshioka, N., Inoue, H. (2010). Spectroscopic studies on the thermodynamic and thermal denaturation of the ct-DNA binding of methylene blue. Spectrochimica Acta Part A, 77, 528-534.

Nishimura, S.I., Kai, H., Shinada, K., Yoshida, T., Tokura, S., Kurita, K., Nakashima, H., Yamamoto, N., Uryu, T. (1998). Regioselective syntheses of sulfated polysaccharides: specific anti-HIV-1 activity of novel chitin sulfates. Carbohydrate Polymers, 306, 427-433.

Qi, H.M., Zhang, Q.B., Zhao, T.T., Hu, R.G., Zhang, K., Li, Z.E. (2006). In vitro antioxidant activity of acetylated and benzoylated derivatives of polysaccharide extracted from Ulva pertusa (Chlorophyta). Bioorganic \& Medicinal Chemistry Letters, 16, 2441-2445.

Rees, D.A. Williamson, F.B. Frangou, S.A. Morris, E.R. (1982). Fragmentation and modification of iota-carrageenan and characterisation of the polysaccharide order-disorder transition in 
solution. European Journal of Biochemistry, 122, 71-79.

Redouan, E. Petit, E., Michelle, P., Courtois, B., Courtois J., Delattre C. (2011). Evaluation of antioxidant capacity of ulvan-like polymer obtained by regioselective oxidation of gellan exopolysaccharide. Food Chemistry, 127, 976-983.

Rout, D., Mondal, S., Chakraborty, I., Islam, S.S. (2008). The structure and conformation of a water-insoluble $(1 \rightarrow 3)-,(1 \rightarrow 6)-\beta$-D-glucan from the fruiting bodies of Pleurotus florida. Carbohydrate Research, 343, 982-987.

Skorik, Y.A., Gomes, C.A. R.,Vasconcelos, M., Teresa, S. D., Yatluk, Y,G. (2003). N-(2-Carboxyethyl) chitosans: regioselective synthesis, characterisation and protolytic equilibria. Carbohydrate Research, 338, 271-276.

Tao, Y.Z., Zhang, L., Peter, C.K. (2006). Physicochemical properties and antitumor activities of water-soluble native and sulfated hyperbranched mushroom polysaccharides. Carbohydrate Research, 341, 2261-2269.

Yi, Y., Zhang, M.W., Liao, S.T., Zhang, R.F., Deng, Y.Y., Wei, Z.C., Yang, B. (2012). Effects of alkali dissociation on the molecular conformation and immunomodulatory activity of longan pulp polysaccharide (LPI). Carbohydrate Polymers, 87, 1311-1317.

Wang, J.L., Guo, H.Y., Zhang, J., Wang, X.F., Zhao, B.T., Yao, J., Wang, Y.P. (2010). Sulfated modification, characterization and structure-antioxidant relationships of Artemisia sphaerocephala polysaccharides. Carbohydrate Polymers, 81, 897-905.

Wang, J.L., Niu, S.F., Zhao, B.T., Luo, T., Liu, D., Zhang, J. (2014). Catalytic synthesis of sulfated polysaccharides. II: Comparative studies of solution conformation and antioxidant activities. Carbohydrate Polymers, 107, 221-231. 
Wang, J.L., Yang, W., Wang, J.C., Wang, X., Wu, F., Yao, J., Zhang, J., Lei, Z.Q. (2015).

Regioselective sulfation of Artemisia sphaerocephala polysaccharide: Characterization of chemical structure. Carbohydrate Polymers, 133, 320-327.

Wang, X.H., Xu, X.J., Zhang, L.N. (2008).Thermally induced conformation transition of triple-helical lentinan in $\mathrm{NaCl}$ aqueous solution. Journal of Physical Chemistry B, 112, 10343-10351.

Wu, Y., Li, W., Cui, W., Eskin, N.A.M., Goff, H.D. (2012). A molecular modeling approach to understand conformation-functionality relationships of galactomannans with different mannose/galactose ratios. Food Hydrocolloids, 26, 359-364.

Zhang, H., Wang, Z.Y., Yang, L., Yang, X., Wang, X., Zhang, Z. (2011b). In vitro antioxidant activities of sulfated derivatives of polysaccharides extracted from Auricularia auricular. International Journal of Molecular Sciences, 12, 3288-3302.

Zhang, J., Wu, J., Liang, J.Y., Hu, Z.A., Wang, Y.P., Zhang, S.T. (2007). Chemical characterization of Artemisia seed polysaccharide. Carbohydrate Polymers, 67, 213-218.

Zhang, R., Edgar, K.J. (2014). Synthesis of curdlan derivatives regioselectively modified at C-6: O-(N)-Acylated 6-amino-6-deoxycurdlan. Carbohydrate Polymers, 105, 161-168.

Zhang, Y., Gu, M., Wang, K.P., Chen, Z.X., Dai, L.Q., Liu, J.Y., Zeng, F. (2010). Structure, chain conformation and antitumor activity of a novel polysaccharide from Lentinus edodes. Fitoterapia 81, 1163-1170.

Zhang, Y.Y., Li, S., Wang, X.H., Zhang, L.N., Peter C.K.C. (2011a). Advances in lentinan: Isolation, structure, chain conformation and bioactivities. Food Hydrocolloids, 251, 96-206. Zhang, Y.Y., Li, S., Zhang, L.N. (2010). Aggregation behavior of triple helical polysaccharide 
with low molecular weight in diluted aqueous solution. Journal of Physical Chemistry B, 114, 4945-4954.

Zhao, T., Mao, G.H., Feng, W.W., Mao, R.W., Gu, X.Y., Li, T., Li, Q., Bao, Y.T., Yang, L.Q., Wu. X.Y. (2014). Isolation, characterization and antioxidant activity of polysaccharide from Schisandra sphenanthera. Carbohydrate Polymers, 105, 26-33. 


\section{Figure Captions:}

Fig. 1 Log-log plot of $M_{\mathrm{W}}$ versus $\left\langle S^{2}\right\rangle_{z}^{1 / 2}$ of ASP, SASP and $\mathrm{S}_{\mathrm{RS}} \mathrm{ASP}$ at $25^{\circ} \mathrm{C}$

Fig. 2 Schematic representation of solution conformation transition after regioselective sulfation

Fig. 3 Circular dichroism spectra of ASP and its sulfated derivatives at $25^{\circ} \mathrm{C}$

Fig. 4 Dye-polysaccharide binding tests (A) Absorption spectra of MB measured from $450 \mathrm{~nm}$ to $750 \mathrm{~nm}$ at different concentrations of $\mathrm{S}_{\mathrm{RS}} \mathrm{ASP}_{4}$ at $20^{\circ} \mathrm{C}$ (B) Evolution of absorption values at $664 \mathrm{~nm}$ and $554 \mathrm{~nm}$ for $\mathrm{S}_{\mathrm{RS}} \mathrm{ASP}_{4}$ as a function of polysaccharide concentrations. (C) Absorption spectra of $\mathrm{MB}$ at different temperatures with $\mathrm{S}_{\mathrm{RS}} \mathrm{ASP}_{4}$ concentration of 0.05 $\mathrm{mg} / \mathrm{mL}$. (D) Evolution of absorption values at $664 \mathrm{~nm}$ and $554 \mathrm{~nm}$ for $\mathrm{S}_{\mathrm{RS}} \mathrm{ASP}_{4}$ as a function of temperatures. (E) Evolution of absorption values of $\mathrm{S}_{\mathrm{RS}} \mathrm{ASP}_{4}-\mathrm{CR}$ as a function of polysaccharide concentrations at $20^{\circ} \mathrm{C}(\mathrm{F})$ Evolution of absorption values of $\mathrm{S}_{\mathrm{RS}} \mathrm{ASP}_{4}-\mathrm{CR}$ as a function of $\mathrm{NaOH}$ concentrations at $20^{\circ} \mathrm{C}$

Fig. 5 2D/3D AFM images and section analysis of $\mathrm{S}_{\mathrm{RS}} \mathrm{ASP}_{4}$ at the concentration of $1 \mu \mathrm{g} / \mathrm{mL}$

Fig. 6 Antioxidant effect of ASP and its sulfated derivatives. Samples with different substitution positions were selected. (A) scavenging activity of DPPH radicals; (B) scavenging activity of superoxide radicals; (C) reducing power evaluation; (D) scavenging activity of hydroxyl radicals; (E) ferrous ions chelating effect; (F) Schematic representation of the formation of chelates; data are presented as mean values $(n=3)$. 